\title{
Ulysses arrangements in psychiatry: from normative ethics to empirical research, and back
}

\author{
Author: Ine Gremmen
}

\subsection{Introduction}

In this chapter I will discuss an example of how empirical research may contribute to normative ethics. The example concerns Ulysses arrangements. How may empirical research into Ulysses arrangements encourage normative ethical thinking about this issue?

I shall first introduce Ulysses arrangements, and give the background to such arrangements in the Netherlands. I will then outline our empirical investigations into this subject. I shall present several results from our study and discuss their relevance for normative thinking on the issues at stake in Ulysses arrangements. I shall argue that our study's results provide material for further normative analysis, including evidence that Ulysses arrangements, as seen from the perspective of caring practices, are different in several important respects from how they are seen from the point of view of their origin in normative analysis.

I do not want to suggest that this is the only way in which empirical work and normative analysis are related to each other. Scientists doing empirical work, for example, inevitably employ normative frameworks: they do not collect and analyse their data 'from nowhere'. I have discussed this aspect of the relationships between empirical work and normative frameworks in previous papers (see Gremmen and Davis 1998, Gremmen 2001) and will not discuss it further in this chapter.

In the last section of the chapter, I shall summarize how our empirical research may enhance normative ethics concerning Ulysses arrangements in psychiatry, and use the results to identify some of the key ethical issues at stake in these arrangements.

\subsection{Background: Ulysses arrangements and the Dutch 1994 Bopz Act}

The research project I will discuss focused on Ulysses arrangements in Dutch psychiatry. The name of the arrangement symbolically refers to the ancient Greek story of Ulysses and the Sirens. When Ulysses and his men sailed home after the Trojan War had ended, they had to cross the region where the Sirens could be heard singing their extremely lovely songs. Many a sailor had drowned after having jumped overboard in an attempt to reach the supposedly equally lovely Sirens. Ulysses found a way to hear the Sirens singing without having to die. He arranged for his men to put wax in their ears (so that they would not hear the Sirens' songs), to bind him tightly to the ship's mast and to ignore his orders. He instructed his men to fasten him even more tightly should he beg or give orders to be released. This arrangement enabled Ulysses to hear the Sirens singing without having to pay for it with his life.

In the field of mental health care, a Ulysses arrangement may be considered a special kind of advance directive for those clients with recurrent episodes of serious psychiatric symptoms, who consider it desirable that others intervene during such episodes, but who, at the same time, have experienced that when in crisis they resist these very interventions. Resistance is taken to include 
unintended and non-violent resistance due, for example, to their not perceiving the seriousness of their condition. Clients with bipolar disorders provide a classic example. In a Ulysses arrangement such clients, at a time when they are not incapacitated by illness, may arrange to be hospitalized, or treated, against their will during a future crisis when they are ill but resisting appropriate care.

Ulysses arrangements would require legal regulation if they are to be used to enforce mental health care. Ulysses arrangements are not currently legal in the Netherlands, but the Dutch Cabinet has proposed to provide for legal regulation of Ulysses arrangements (Kamerstukken 2001/02, 2002/03, $\underline{2004 / 05}, \underline{2005 / 06}$.

The Dutch debate concerning Ulysses arrangements was initiated by Berghmans, a health care ethicist (Berghmans 1992; Widdershoven and Berghmans 2001). He suggested that Ulysses arrangements may be considered a form of 'auto-paternalism': clients decide for themselves what is in their best interests in a future situation of psychosis. The immediate cause for con sidering the legal regulation of Ulysses arrangements in psychiatry were some problems in the 1994 Bopz Act on mental health care (Bijzondere Opnemingen in Psychiatrische Ziekenhuizen, i.e. Special admissions into psychiatric hospitals).

The Bopz Act is principally concerned with involuntary admission into psychiatric hospitals. Until the introduction of the Bopz Act in 1994, involuntary admission could be legally justified in terms of the best interests of clients. Clients could be admitted against their will 'for their own good', which had to be reviewed by a judge, on the basis of a psychiatrist's judgement. The Bopz Act abandoned the 'for their own good' principle. This principle had come to be considered too paternalistic.

The Bopz Act takes the principle of self-determination to be the overriding normative principle for admission into psychiatric institutions. As a consequence, clients may be admitted against their will only if they can be considered to cause 'danger to themselves or to others', if the danger stems from the client's 'mental disorder', and if there is no other way to avert it. Once admitted, clients may be treated against their will only if involuntary treatment is the only way to avert danger due to the client's mental illness.

Since its introduction, the Bopz Act has been criticized for being too restrictive. Psychiatric illnesses can cause much harm even when clients can not (or not yet) be considered to cause danger to themselves or to others using the criteria of the Bopz Act. When these clients resist admission, treatment, or any other help, there is no legal power to intervene against the clients' will, as might have been the case according to the 'for their own good' principle. The clients' wishes not to receive care will have to be respected, in accordance with the autonomy principle. The evaluation of the Bopz Act, in 1996/97, resulted in several proposals to partially solve this dilemma between respect for clients' autonomy (that might result in unjustified indifference) and care for clients' well-being (that might result in unjustified interference). One proposal is to introduce a new legal option for enforced admission or treatment, namely the so-called 'Ulysses arrangement' ('zelfbinding' in Dutch). ${ }^{1}$

Ulysses arrangements might provide a legally accepted way for health care professionals to overrule an incapacitated client's resistance, without the legal conditions of 'danger to themselves or others' being met. This could prevent the harmful consequences that would result from not enforcing admission or treatment. The Dutch Cabinet reasons that overruling a client's will on the basis of a Ulysses arrangement may be morally and legally justified as it can be 'traced back to the patient's own wishes' (Kamerstukken 2001/02, No. 3). According to the Cabinet, Ulysses arrangements may be considered to be an expression of patient autonomy, and, therefore, a form of 'care according to 
needs' (Ministerie van Volksgezondheid et al. 1997), rather than simply reverting to the paternalism that was inherent in the legislation before the Bopz Act.

Since Ulysses arrangements would concern involuntary admission and/or treatment in situations where the legal conditions for involuntary admission or treatment are not (or not yet) met, these arrangements would undermine the Bopz Act's conditions of 'danger'. The Cabinet resolves this problem by reasoning that Ulysses arrangements can be considered consistent with the Bopz Act's central principle of respect for patient autonomy, provided that drafting the arrangement can be guaranteed to be an autonomous act by the clients concerned. In line with this reasoning, the Dutch Cabinet has proposed a supplement to the Bopz Act in order to make Ulysses arrangements a legal option.

The current debate taking place in the Netherlands illustrates one way in which normative ethics, caring practices, policy, and the law relate to each other. The Bopz Act was guided by the normative position that respect for patient autonomy (patient self-determination) should override 'paternalistic' considerations of best interests. Mental health care practice suggests that there are problems with the working of the Bopz Act. In particular the Act does not allow intervention to be enforced at an early stage in a mental illness when it may be effective in preventing further deterioration. This sometimes results in clients coming to greater harm and does not prevent, but only delays, enforced treatment. On the basis of normative ethics, Ulysses arrangements are proposed as one solution to this problem. They may prevent the harmful effects of delayed intervention, but in a way that is in keeping with the principle of respect for patient autonomy rather than returning to the principle of best interests.

The purpose of the empirical research discussed in this chapter is to continue the interaction between normative ethics and empirical data through investigating the likely consequences of adopting a Ulysses arrangement within the legal structure around enforcing psychiatric care. While the proposal for Ulysses arrangements was developed and discussed in normative terms (as a way of respecting patient autonomy), it is relevant, as well, to empirically assess the effects of Ulysses arrangements as a mental health care intervention, in the same way as one might assess the effects of any other health care intervention, e.g. a drug treatment.

I shall argue that our empirical data suggest that Ulysses arrangements, as seen from the perspective of caring practices, differ from Ulysses arrangements as seen from the principle of autonomy described above. As a consequence, the data raise further issues for normative analysis.

\subsection{The research project: policy analysis and interview study}

In order to investigate the ethical and juridical aspects of Ulysses arrangements further, the Dutch Cabinet asked the Netherlands Organization for Scientific Research (NWO) to fund research on the ethical and legal issues involved. The research project described in this chapter was undertaken as a result (Gremmen et al. 2002). The project (1999-2002) was supervised by Prof S. Sevenhuijsen (Utrecht University) and Prof G. Widdershoven (Maastricht University), who are experts on feminist ethics of care and health care ethics, respectively (e.g. Sevenhuijsen 1998, 1999; Widdershoven 1999; Widdershoven and Berghmans 2001). Dr I. Gremmen was the main executive researcher. Co-workers in the project were independent legal expert and psychiatrist $\mathrm{Mr} \mathrm{R}$. Zuijderhoudt, and psychiatrist Dr A. Beekman (Amsterdam Free University). The project was approved by the ethical committee of Utrecht University. 
Our research entailed two studies. In the first study, we undertook an analysis of the Dutch policy debate concerning Ulysses arrangements. The results of this study are discussed elsewhere (Gremmen et al. 2002). In our second study, we investigated the experiences and considerations of persons practically or potentially involved with the issue of Ulysses arrangements. Semi-structured interviews were conducted with 18 clients, 12 of their partners, family members, or friends, 17 professional care providers, e.g. psychiatrists and psychiatric nurses, and 19 others involved, e.g. lawyers, judges, and clients' trusted representatives.

The clients were approached first. They were found through clients' interest groups, clients' boards in mental health care institutions, and professional care providers. If clients agreed (with written permission), their family members or professional care providers were invited to participate in the project as well. This procedure enabled us to collect views of the situation from different angles. The majority of clients interviewed agreed to our approaching others involved in their care. Some additional interviews were held with family members and professional care-givers who were not connected to the clients involved in the study. One of the professional care-givers is $\mathrm{R}$, a psychiatrist whose story will be discussed below. Judges and lawyers were found through the members of the research group, and clients' trusted representatives through their professional organization.

The interviews focused on the interviewees' experiences relevant to the issue of Ulysses arrangements, and on their considerations concerning the moral and legal grounds, the goals, and the advantages and disadvantages of Ulysses arrangements. The interview material was systematically analysed by theme. Interviewees' stories about experiences with Ulysses-like arrangements were studied in detail through line-by-line analysis.

In this chapter, two main findings of our second study (the interview study) will be discussed. Both provide 'food for normative ethics' concerning the issue of Ulysses arrangements. The first finding concerns a paradox: interviewees consider the prevention of involuntary admission or treatment as one of the aims of Ulysses arrangements. The second finding concerns several moral dilemmas that the interviewees formulate concerning putting a Ulysses arrangement into effect through involuntary admission or treatment. At first glance, both findings seem to be at odds with current ethical reasoning concerning Ulysses arrangements in psychiatry (e.g. Elster 1984, 2000), and with the reasoning of the Dutch Cabinet. How could one want to prevent coercion by prearranging for this very same coercion? And wouldn't the ethical problems concerning coercion be solved through freely and deliberately prearranging for it in a Ulysses arrangement?

\subsection{The paradox of prevention: avoiding coercion through prearranging for it}

The first finding of our interview study that we will discuss is the interviewees' (somewhat paradoxical) expressed wish to prevent coercion by means of making a Ulysses arrangement. Several interviewees in this study say that they want to use a Ulysses arrangement in order to plan for involuntary admission or treatment if in the future they become psychotic, in order to prevent what one client calls the 'more heavy' alternative of being arrested by the police.

Some clients predict that, if they are to make a Ulysses arrangement, then they will not resist the measures agreed to in that agreement, in a future situation of crisis. This may sound optimistic, given that they showed resistance in the past. Other clients do predict that they will resist coercive measures even if these are in line with an agreed Ulysses arrangement. Consider the interview with a client, $\mathrm{D}$, who is diagnosed as having a bipolar disorder. $\mathrm{D}$ has been involuntarily admitted twice in the past, after having turned his house into a complete mess and having annoyed his neighbours 
to the point of police involvement. D says that he would consider drafting a Ulysses arrangement if it were a legal option, in order to prevent the damage of another episode of psychosis. When asked how he imagines the Ulysses arrangement working, he replies that he expects to resist admission, particularly as he will probably feel quite well. Nevertheless he hopes that he will be persuaded to agree to admission: the arrangement might 'encourage me to have myself admitted, anyway, possibly against my will.'

Other clients express similar views and use similar words. At first glance, what these clients are saying seems not just optimistic, but illogical. How could one agree to admission against one's will? I shall discuss one example from our interview study more extensively, in order to explore these considerations in detail. The example is from an interview with a psychiatrist, $\mathrm{R}$.

$\mathrm{R}$ drafted a Ulysses arrangement with one of his clients 4 years ago, although, of course, it had no legal standing. The client, Ms M, had been diagnosed as having a bipolar disorder. During the 7 years before the Ulysses arrangement was drafted, Ms M was involuntarily admitted several times, after causing serious marital problems which required police intervention and led to her husband leaving home. On these occasions Ms M was admitted involuntarily at a time when, in her view, nothing was the matter with her.

The point was reached where her husband was seriously considering divorce. By then, it had become clear, after a crisis leading to involuntary admission, that Ms M had been mildly manic for about a year and that this was a major cause of the marital problems.

After Ms M regained her stability, $\mathrm{R}$ suggested that Ms and Mr M consider the option of making a Ulysses arrangement. He reasoned that the arrangement might provide the crucial support that Ms $\mathrm{M}$ needed in order to break through the cycle of recurrent episodes of psychiatric symptoms. Ms M agreed to draft a Ulysses arrangement and to oversee its content and consequences. $\mathrm{R}$ considered it very important that Ms M had control over the agreement. He realized that Mr M's signing the agreement amounted to 'giving up a bit of autonomy'. He did not agree however with the view of several other interviewees that respecting autonomy implies that clients, rather than care-givers, should initiate the discussion around drafting a Ulysses arrangement.

Ms M was quite motivated to avoid the damage due to her symptoms and did not have too much of a problem with the idea of giving up some autonomy in future crises. Mr M told $\mathrm{R}$ that he would prefer to try and live with some symptoms from time to time, to having a divorce, as long as there was someone for him to turn to for help before a crisis point was reached.

In consultation with $\mathrm{Ms}$ and $\mathrm{Mr} \mathrm{M}, \mathrm{R}$ drafted an arrangement to cover the situations when Ms M would need involuntary admission. In drafting the arrangement he took account of the Dutch literature on Ulysses arrangements (e.g. Berghmans). He arranged for an official ceremony for the signing of the final draft, with Ms M's brother, whom she trusted, present as a witness. R believed that the ceremony might help Ms M to remember the arrangement were she to become psychotic and that it would enable both $\mathrm{Mr} \mathrm{M}$ and himself to refer more easily to the arrangement in discussions with Ms $\mathrm{M}$ at such a time.

In fact involuntary admission has never been needed over the 4 years since the Ulysses arrangement was agreed. $\mathrm{R}$ believes that this is because he has been able to take immediate action whenever Ms $\mathrm{M}$ begins to be unwell, as signalled either by herself or by Mr M. When either of them calls $\mathrm{R}$ for help, he arranges an appointment within a few days. On one occasion there was some quarrelling and disagreement between $\mathrm{Ms}$ and $\mathrm{Mr} \mathrm{M}$, but not the serious fights that had previously taken place. In contrast to previous occasions, Ms $\mathrm{M}$ herself raised the alarm and agreed to being admitted. 
Furthermore, whereas on previous occasions she stayed in hospital for several months, on this occasion, she was discharged after 10 days.

Although from time to time the situation is 'not easy' for Mr and Ms M, R considers it 'quite bearable for all involved'. Ms and Mr M can accept that times are hard, now and again. There is no longer any question of their getting divorced.

R's story suggests that Ulysses arrangements are playing a role that is different from how they were conceived. They are not just about respect for patient autonomy providing a rationale for coercive treatment. They may affect the relationships between clients and health professionals; they may impact on trust; and they may affect the behaviour and decisions made by clients as well as professionals, reducing the need for coercive treatment. These are issues that are relevant to ethical analysis.

Psychiatrist $\mathrm{R}$ is convinced that the involuntary admission of Ms $\mathrm{M}$ has been avoided as a result of the Ulysses arrangement. He explains that 'initially' he thought that a Ulysses arrangement 'primarily had a juridical, contractual tone'. While working with it, however, in practice, to his 'surprise', R has experienced that, even though it is 'of course' partly contractual, some 'quite different processes' were also set in motion. 'It may not be primarily what a Ulysses arrangement is meant for,' R says, 'but it is a definition of the treatment relationship in terms of mutual obligations, as well'. R characterizes the redefined relationship between Ms M and himself as one of 'greater equality'.

In R's experience, making a Ulysses arrangement implies that he commits himself to respond to an appeal for help from Ms M. This is an obligation not only to intervene quickly when a crisis develops, but also to be prepared if necessary to admit Ms M to hospital. Ms M, in turn, agrees to be admitted if $\mathrm{R}$ and $\mathrm{Mr} \mathrm{M}$ consider this necessary, even if she resists admission at the time.

$\mathrm{R}$ says that he feels he could refer to the agreement in a crisis situation, reminding Ms $\mathrm{M}$ that it has been discussed extensively and that she has clearly agreed to the arrangement. $\mathrm{R}$ has never in fact had to refer to the Ulysses arrangement in this way. It is his experience 'that a Ulysses contract is not just a sort of juridical means of coercion. It confirms the treatment relationship, as well, thus encouraging clients to stick to the agreements made, even when they may not realise or want to, later on'. It may be worth noting the similarity with client D's expression, cited earlier, who hopes to 'have myself admitted, possibly against my will'. Other interviewees explained, that, in a relationship of trust with a care-giver, clients may cooperate rather than resist care in a situation when, due to a psychosis, they neither remember the earlier agreement nor are able to rehearse the arguments in favour of the arrangement. One interviewee, for example, told how a client allowed himself to be taken to a psychiatric hospital by a professional, while heavily protesting verbally at the same time. By that time, as the interviewee put it, 'his head did not remember that he could trust the care-giver, but his feet still knew it'.

While a Ulysses arrangement may be made in order to break through the 'seemingly unavoidable cycle' of recurring episodes of crisis where 'things get completely out of control', R considers that experiencing both the 'extra safety' and the mutuality of the arrangement creates 'quite some room', enabling clients to find a 'new way of seeing and dealing with their symptoms'. For example, a Ulysses contract helps clients to feel that they are 'a full partner in a contract, rather than a passive victim who is just being told to do things by someone else. You see? Kind of partner in the problem. All involved are confronted with the problem and we very carefully arrange for dealing with it. You see? It implies that I have to stick to the agreement, as well. It's a different way of looking at it.' 
R says that the client's assumption of responsibility 'has been the most important effect, I think, in retrospect.' Clients may experience the new way of dealing with their symptoms as more satisfying, which in turn encourages them to go on with it. In the end, they may intervene just before they stop having insight into their symptoms, and before they resort to complete resistance. 'That's the idea, actually,' R says. The Ulysses arrangement appears to enable a self-sustaining process of change. 'But that's just an effect, it's an extra,' R adds, 'and it remains to be seen how often it happens. But it struck me, you know? Thinking is so much in terms of coercion. But if it comes on the one side, it comes on the other side as well, you see? For, in the end, you do hope that as little coercion as possible is ... and that might very well be a side benefit.'

\subsection{Enhancing normative thinking on Ulysses arrangements: preventing the need for coercion}

The story of R illustrates how a Ulysses arrangement might prevent the need for coercion, thus suggesting an explanation for the paradox of aiming at the prevention of coercion through prearranging for this very same coercion. In R's experience, a Ulysses arrangement redefines the relationship between the client and himself into a more equal, cooperative, and mutual one as well as redefining the client's role towards her symptoms into a more active, rather than passive one. By creating 'extra safety' (describing the steps to be taken when the situation develops into a crisis) and by committing himself to agreements he can stick to in practice, such as making an appointment and admitting to hospital if necessary, $\mathrm{R}$ encourages $\mathrm{Ms} \mathrm{M}$ to feel confident about taking more responsibility for dealing with her symptoms. This has the effect of preventing relapse of psychosis through her taking precautionary measures in time. In R's view, this is 'the most important effect'. It is the aim one would want to achieve using Ulysses arrangements, even though they are discussed 'so much in terms of coercion'.

$\mathrm{R}$ is aware that his experiences may not be fully in line with the ethical literature on Ulysses arrangements. He himself is surprised by how the arrangement with Ms M is working out in practice and marginalizes his experiences in so far as they do not fit easily into current ethical reasoning. He states, for example, that what he has experienced as 'the most important effect' 'may not be primarily what a Ulysses arrangement is meant for'. The prevention of coercion might 'just' be 'an extra', 'a side benefit'.

Rather than going along with this marginalization, however, normative ethics might take R's experiences and considerations as an encouragement to broaden current normative reasoning on Ulysses arrangements. Put differently: R's story might show that there may be more to say about Ulysses arrangements than that they might be (or not be) legitimated on the basis of clients' free and well informed autonomous decisions to opt for them. First, drafting a Ulysses arrangement may not amount only to exercising one's autonomy as a client; it may also imply giving up some of one's autonomy. Second, Ulysses arrangements might 'work', not just because clients autonomously opt for them, but because drafting the arrangement may enable both clients and care-givers to look differently at, and deal differently with, psychiatric symptoms. The story of R, among others, may encourage normative ethics to go into the conditions and effects of Ulysses arrangements more deeply, taking into account ethical issues additional to those around autonomy, such as those of dealing with vulnerability ('extra safety'), creating and maintaining trust ('confidence'), mutuality ('cooperation'), and taking - and entrusting - responsibility. 


\subsection{Moral dilemmas concerning precommitment for coercion}

The experience of psychiatrist R suggests that Ulysses arrangements would require continuous relationships of trust between clients and care-givers. They also require that the arrangements are drafted in the context of mutually agreed, and realistic, crisis plans and that there is a context of reliable caring services. It might be argued that, to the extent that these conditions are met, Ulysses arrangements might not be needed at all because under these conditions severe crises and coercion are likely to be avoided. However, our main finding opposing this argument concerns interviewees' experience that, in situations of crisis, good relationships and mutually agreed upon crisis plans may not suffice to maintain the contact and communication that are necessary for the prevention of severe psychosis and coercion. R himself, for example, suggests that a Ulysses arrangement may have to exist for many years (and have a strong juridical status, as well) since some clients' conditions may deteriorate within such a short period of time that contact with these clients may be lost too quickly and to too great an extent in a crisis situation. In these situations, the prevention of coercion has less chance of success than in the case of Ms M. A Ulysses arrangement may then have to be put into its ultimate effect, i.e. by involuntary admission or treatment.

From our interview material it appears that involuntary admission or treatment continues to be a moral issue even if freely and deliberately agreed through a Ulysses arrangement. I shall briefly present our findings, as they may provide further 'food' for normative thinking.

None of the clients in our study was being treated or admitted to hospital involuntarily at the time of the interview. However, most have experienced involuntary admission in the past. All have experienced limitations on their will, e.g. to their freedom to move. One example is that family members took away or hid car keys at times of developing crises. When asked, clients say that they do not expect to experience coercion (e.g. involuntary admission or treatment) on the basis of a Ulysses arrangement as different from coercion on any other basis. They expect that they will have the same feelings of not being taken seriously, of having nothing to say, of not being heard and seen, of having been cheated, of being intruded upon and being abandoned, of 'having lost'. They expect to feel as humiliated, isolated, or scared as before. On the other hand they also say that they will expect the other people involved to take the action agreed in the Ulysses arrangement when appropriate, and that if such action is not taken they will also feel cheated and not taken seriously. 'Why didn't you take the measures we arranged for' they might ask, reproachfully, after having recovered.

Similar themes are raised by family members and professional care-givers. On the basis of past experience they expect that clients, to say the least, may not like involuntary measures being initiated. Clients may feel abandoned by the people (or even the one last person) they trusted, and they may not want to see these persons for some time, as a result. At the same time, family members and professional care providers consider that, at that point in time, initiating involuntary measures may be 'the only way to help' the clients involved. As one professional explains: ultimately, Ulysses arrangements are arrangements of 'power inequality'. The care-giver can 'dominantly prescribe what the client has to do'. At the same time, however, Ulysses arrangements may 'guarantee' that the client 'will not be abandoned' when a crisis occurs. 'If collaborative efforts wouldn't work' to prevent deterioration of a client's condition, a Ulysses arrangement may provide a care-giver with 'one last recourse to help you', implying that 'I could do something about you that you would not agree with at that moment'.

Apparently, to 'do something about you that you would not agree with at that moment' may amount to 'help[ing] you'. Put differently: coercion and help (care), while not going easily together, may be closely intertwined when putting a Ulysses arrangement into its ultimate effect. As a consequence, 
putting a Ulysses arrangement into its ultimate effect appears to entail several moral dilemmas for both clients and care-givers involved.

One dilemma is that providing care (e.g. by admitting a client into a psychiatric hospital) would, at this point, involve coercion (the measure would be taken against the client's will). However, not resorting to coercion (not overruling the client's will) would involve abandoning the client (no care would be provided). Clients face a similar dilemma: receiving care would involve undergoing coercion, while refusing coercion would result in being abandoned (getting no care).

Another dilemma concerns trust. Putting a Ulysses arrangement into its ultimate effect puts trust in the relationships between clients and care-givers under serious strain, but so does failing to use the coercion agreed to in the arrangement. Whatever the professional does, the client may feel abandoned and not taken seriously.

These dilemmas imply that the evaluation of the arrangement's being put into its ultimate effect would be an essential element of Ulysses arrangements. The care-givers would have to try and restore trust in the relationship with the client and to account for the steps taken, both to the client and to others, as soon as possible afterwards. The interview material makes it clear that it would not suffice to say: 'I just did what you as a client freely agreed to in advance'. One example is provided by an interviewee, whose daughter has experienced severe psychotic episodes. In the past, she has experienced her daughter's fierce resistance to admission. She expects that a Ulysses arrangement will make her feel relieved because it may, at last, provide a means of protecting her daughter from the harm she has been doing to herself and others when psychotic. If a Ulysses arrangement had been agreed she could say to her daughter: 'This is what you yourself agreed to. It's all your own doing, so, here you go [into the hospital]!' Her argument might be grounded in a concept of autonomy as free and deliberate choice. But the interviewee does not appear to feel happy to rely only on respecting her daughter's previously expressed wishes. She seems to feel that there are still moral problems. When asked to imagine her daughter being admitted under the Ulysses agreement she says that she would want to say to her daughter: 'It's not to punish you, it's to help you!'

\subsection{Enhancing normative thinking on Ulysses arrangements: the issue of responsibility}

The interview material, again, shows that, from a normative ethics perspective, there may be more to say about Ulysses arrangements than that they should be drawn up freely and without coercion.

The interview data suggest that the issue of responsibility also needs to be taken into account. Putting a Ulysses arrangement into its ultimate effect amounts to putting an end to the mutuality of the arrangement, even if only temporarily. Deciding if and when to use the involuntary measures agreed upon earlier is the care-givers' responsibility. As a consequence, care-givers would have to account for the steps taken. They would also need to try and restore trust in the relationship with the client.

The interview material also suggests that another important ethical issue in putting a Ulysses arrangement into its ultimate effect is that, in such a situation, coercion and care are intertwined. Moral dilemmas do result, since coercion and care do not sit easily together. The dilemmas are difficult to deal with from a perspective of individual autonomy conceived of as negative freedom (i.e. the right to non-intervention). In this conception of autonomy, care is easily associated with undue intrusion and paternalism (cf. MacKenzie and Stoljar 1999, Verkerk 1999). Put differently: a concept of autonomy as negative freedom implies a strong opposition between autonomy and beneficence in the setting of treatment coercion. As a result, the issues of whether, when, and under 
what conditions good mental health care might, in specific cases, imply coercion, might be left undiscussed or, for that matter, be marginalized, too easily. However, the interview data suggest that these issues may be of critical importance for normative thinking on Ulysses arrangements.

\subsection{Concluding remarks}

The main empirical findings on Ulysses arrangements discussed in this chapter concern the paradox of preventing involuntary measures by prearranging for them, and the moral dilemmas inherent to situations where coercion and care are closely interconnected. Neither one of these empirical findings may be sufficiently taken into account if a Ulysses arrangement is conceptualized only as freely and deliberately prearranged involuntary admission or treatment. Furthermore, both these findings might, in turn, enhance normative thinking on Ulysses arrangements. There may be more to say on Ulysses arrangements, from a normative perspective, than a concept of autonomy as rational choice and negative freedom readily allows. The interview data may encourage normative thinking on Ulysses arrangements as a process and as a relationship. Ethical issues of dealing with vulnerability, mutual commitment, and the taking and entrusting of responsibility might be incorporated. The idea of coercion as a form of care, however contested, might be considered.

In addition to issues around autonomy, I suggest the following description of the ethical issues at stake in Ulysses arrangements. Considering and drafting a Ulysses arrangement would require that clients recognize their vulnerability for psychoses. A Ulysses arrangement might then be considered a process in which clients take responsibility to formulate their caring needs for future situations of crisis, and entrust care for their well being in these situations to others (either whole-heartedly or as a felt necessity). Ulysses arrangements may be considered mutual arrangements, in which not just the clients, but the other persons involved clarify their responsibilities and competencies, in order to build trust in the relationship and make the arrangement work in practice. Drafting the arrangement, and working with it, may enhance confidence as well as provide opportunities to deal with a developing crisis at an early stage, thus avoiding coercion. Having to put a Ulysses arrangement into its ultimate effect (i.e. through coercion) is problematic, even though this has been arranged for in advance. It would, at least temporarily, undermine the mutual character of the arrangement and result in several moral dilemmas. Even though coercion has been arranged for as an ultimate form of care, coercion and care do not sit easily together. Coercion puts trust at severe risk. As a consequence, both the prevention of coercion as well as the evaluation of coercive measures (responsiveness, accountability, restoration of trust) may be considered to be of central importance.

The issues discussed in this chapter suggest that the concept of care is a key issue in normative thinking about Ulysses arrangements. In other words: normative ethics might take the paradoxes and controversies in the interview data described in this chapter into account through a consideration of the issue of good care.

\section{References}

Berghmans R (1992). Om bestwil. Paternalisme in de psychiatrie. Thesis Publishers, Amsterdam.Find this resource:

Davis K and Gremmen I (1998). In search of heroines: some reflections on normativity in feminist research. Feminism \& Psychology 8(2), 133-53.Find this resource:

Elster J (1984). Ulysses and the Sirens: studies in rationality and irrationality, 2nd revised edn. Cambridge University Press, Cambridge.Find this resource: 
Elster J (2000). Ulysses unbound: studies in rationality, precommitment and constraints. Cambridge University Press, Cambridge.Find this resource:

Gremmen I (2001). Interpretatief zorgethisch onderzoek in de praktijk. Medische Antropologie, 13(2), 323-39.Find this resource:

Gremmen I, Sevenhuijsen S, Widdershoven G, Beekman A and Zuijderhoudt R (2002). Zelfbinding in de psychiatrie, een kwestie van goede zorg? NWO/Universiteit Utrecht, Den Haag/Utrecht.Find this resource:

Kamerstukken II (2001/02). 28283 nrs 1-4. Wijziging van de Wet bijzondere opnemingen in psychiatrische ziekenhuizen (zelfbinding).Find this resource:

Kamerstukken II (2002/03). 28283 nrs 5-7. Wijziging van de Wet bijzondere opnemingen in psychiatrische ziekenhuizen (zelfbinding).Find this resource:

Kamerstukken II (2004/05). 28283 nrs 8-9. Wijziging van de Wet bijzondere opnemingen in psychiatrische ziekenhuizen (zelfbinding).Find this resource:

Kamerstukken II (2005/06). 28283 nrs A, B and 10-16. Wijziging van de Wet bijzondere opnemingen in psychiatrische ziekenhuizen (zelfbinding).Find this resource:

MacKenzie C and Stoljar N eds. (1999). Relational autonomy: feminist perspectives on autonomy, agency and the social self. Oxford University Press, New York and Oxford.Find this resource:

Ministerie van Volksgezondheid, Welzijn en Sport (VWS) and Ministerie van Justitie (1997). Kabinetsstandpunt: Evaluatie van de Wet BOPZ. Ministeries van VWS en Justitie, Rijswijk. Find this resource:

Sevenhuijsen S (1998). Citizenship and the ethics of care: feminist considerations on justice, morality and politics. Routledge, London/New York.Find this resource:

Sevenhuijsen S (1999). Too good to be true? Feminist considerations about trust and social cohesion. Focaal, 34, 207-22.Find this resource:

Verkerk M (1999). A care perspective on coercion and autonomy. Bioethics, 13(3-4), 358-68.Find this resource:

Widdershoven G (1999). Care, cure and interpersonal understanding. Journal of Advanced Nursing, 29, 1163-9.Find this resource:

Widdershoven G and Berghmans R (2001). Advance directives in psychiatric care: a narrative approach. Journal of Medical Ethics, 27(2) 92-7.Find this resource:

\section{Notes:}

${ }^{1}$ In the literature on Ulysses arrangements in psychiatry, the terms 'Ulysses contract' or 'Ulysses statement' can be found, as well. In our project we preferred the term Ulysses 'arrangement'. The term 'contract' is problematic in that it assumes a legal status, which is not evident; 'statement' has the connotation of a one-sided declaration, whereas the term 'arrangement' makes clear that both clients and others are involved. 